\title{
Prokinetics for the treatment of functional dyspepsia: Bayesian network meta-analysis
}

\author{
Young Joo Yang, Chang Seok Bang* (D), Gwang Ho Baik, Tae Young Park, Suk Pyo Shin, Ki Tae Suk \\ and Dong Joon Kim
}

\begin{abstract}
Background: Controversies persist regarding the effect of prokinetics for the treatment of functional dyspepsia (FD). This study aimed to assess the comparative efficacy of prokinetic agents for the treatment of FD.

Methods: Randomized controlled trials (RCTs) of prokinetics for the treatment of FD were identified from core databases. Symptom response rates were extracted and analyzed using odds ratios (ORs). A Bayesian network metaanalysis was performed using the Markov chain Monte Carlo method in WinBUGS and NetMetaXL.

Results: In total, 25 RCTs, which included 4473 patients with FD who were treated with 6 different prokinetics or placebo, were identified and analyzed. Metoclopramide showed the best surface under the cumulative ranking curve (SUCRA) probability (92.5\%), followed by trimebutine (74.5\%) and mosapride (63.3\%). However, the therapeutic efficacy of metoclopramide was not significantly different from that of trimebutine (OR:1.32, 95\% credible interval: 0.27-6.06), mosapride (OR: 1.99, 95\% credible interval: 0.87-4.72), or domperidone (OR: 2.04, 95\% credible interval: 0.92-4.60). Metoclopramide showed better efficacy than itopride (OR: 2.79, 95\% credible interval: 1. 29-6.21) and acotiamide (OR: 3.07, 95\% credible interval: 1.43-6.75). Domperidone (SUCRA probability 62.9\%) showed better efficacy than itopride (OR: 1.37, 95\% credible interval: 1.07-1.77) and acotiamide (OR: 1.51, 95\% credible interval: 1.04-2.18).

Conclusions: Metoclopramide, trimebutine, mosapride, and domperidone showed better efficacy for the treatment of FD than itopride or acotiamide. Considering the adverse events related to metoclopramide or domperidone, the short-term use of these agents or the alternative use of trimebutine or mosapride could be recommended for the symptomatic relief of FD.
\end{abstract}

Keywords: Comparative effectiveness research, Functional dyspepsia, Network meta-analysis, Systematic review, Prokinetics

\section{Background}

Functional dyspepsia (FD) is a common condition in clinical practice [1]. According to the Rome III and IV criteria, FD is defined as the presence of at least one of the following symptoms; postprandial fullness, early satiation, epigastric pain or burning, without evidence of structural disease to explain the symptoms fulfilling time criteria for the last three months with symptom onset at least six months before diagnosis and a frequency of at least three days per week $[2,3]$. FD is subcategorized

\footnotetext{
* Correspondence: csbang@hallym.ac.kr

Department of Internal Medicine, Hallym University College of Medicine,
Chuncheon Sacred Heart Hospital, Sakju-ro 77, Chuncheon, Gangwon-do

Department of Internal Medicine, Hallym University College of Medicine,
Chuncheon Sacred Heart Hospital, Sakju-ro 77, Chuncheon, Gangwon-do 24253, Republic of Korea
}

(c) The Author(s). 2017 Open Access This article is distributed under the terms of the Creative Commons Attribution 4.0 International License (http://creativecommons.org/licenses/by/4.0/), which permits unrestricted use, distribution, and reproduction in any medium, provided you give appropriate credit to the original author(s) and the source, provide a link to the Creative Commons license, and indicate if changes were made. The Creative Commons Public Domain Dedication waiver (http://creativecommons.org/publicdomain/zero/1.0/) applies to the data made available in this article, unless otherwise stated.

into two distinct conditions, which are postprandial distress syndrome, associated with meal-induced bothersome fullness or early satiation, and epigastric pain syndrome, showing bothersome epigastric pain or burning [2, 3].

This condition involves complex pathophysiologic mechanisms and shares overlapping symptoms with gastroesophageal reflux disease or other functional gastrointestinal disorders. The mainstay of the treatment of FD has been to target gastric acid secretion and impaired gut motility. The role of acid inhibitory drugs in the treatment of FD is well established [4]. In a subtype of $\mathrm{FD}$, the response rate of epigastric pain syndrome to 
acid inhibitory therapy is known to be better than that of post-prandial distress syndrome [5].

Excluding acid inhibitory therapy, prokinetics are the mainstay of the treatment of FD. However, the role of prokinetics has not been well established, and inconsistent results have been reported regarding the therapeutic efficacy of each drug [6-10]. Moreover, previously published pairwise meta-analyses were conducted by examining several drugs with different mechanisms of action as a single group, which cannot present the efficacy of each prokinetic agent $[8,9]$. However, head-to-head efficacy comparison of prokinetic agents in the treatment of FD is not easy and pooled comparative efficacy has not been established.

Unlike traditional pair-wise meta-analysis, network meta-analysis enables comparing more than 2 treatments strengthening the precision in the estimate and presenting relative effect sizes in a rank order [11]. Therefore, this study aimed to evaluate the comparative effectiveness of each prokinetic in the treatment of FD using an indirect comparison method.

\section{Methods}

\section{Literature search}

A systematic review was conducted using electronic databases. MEDLINE (PubMed), EMBASE, and the Cochrane Central Register of Controlled Trials (CENTRAL) in the Cochrane Library were searched using common keywords related to FD and prokinetics (inception to July 2015). The keywords were as follows: 'functional dyspepsia', 'prokinetics', 'mosapride', 'itopride', 'trimebutine, 'metoclopramide', 'domperidone', and 'acotiamide', drawn from $\mathrm{MeSH}$ or Emtree terminology and using Boolean operators. Only publications involving human subjects were searched. The bibliographies of relevant articles were also reviewed to identify additional studies. The language of publication was not restricted and all publications except Korean and English were translated using commercial translation service.

\section{Selection criteria}

We included only randomized controlled trials (RCTs) meeting all of the following criteria: 1) designed to evaluate FD in the target or control group; 2) included a group that was given prokinetics and a comparison group that was given placebo or other prokinetics; and 3) presented comparative outcomes about symptomatic relief rates of FD after treatment. Exclusion criteria were as follows: 1) incomplete data or 2) review article.

\section{Selection of relevant studies}

Two of the authors (C.S.B. and G.H.B.) independently evaluated the eligibility of all studies retrieved from the databases based on the predetermined selection criteria.
The abstracts of all identified studies were reviewed to exclude irrelevant articles. Full-text review was performed to determine whether the inclusion criteria were satisfied by the remaining studies. Disagreements between the two evaluators were resolved by discussion or by consultation with a third author (D.J.K.).

\section{Assessment of methodological quality}

The methodological quality of the enrolled studies was assessed using the Risk of Bias table (RoB). The RoB was assessed as described in the Cochrane handbook by recording the method used to generate the randomization sequence, allocation concealment, the determination of whether blinding was implemented for participants or staff, and whether there was evidence of selective reporting of the outcomes [12]. Review Manager version 5.3.3 (Revman for Windows 7, the Nordic Cochrane Centre, Copenhagen, Denmark) was used to generate the RoB table. Two of the authors (C.S.B. and G.H.B.) independently evaluated the methodological quality of all studies, and any disagreements between the two evaluators were resolved by discussion or by consultation with a third author (D.J.K.).

\section{Statistical analysis}

We investigated the efficacy of prokinetics for the treatment of FD using odds ratios (ORs). We calculated the ORs based on an intention-to-treat analysis, when possible, from the original articles to compare the efficacy of prokinetics for the treatment of FD. Network meta-analyses were conducted using the Bayesian Markov Chain Monte Carlo method in WinBUGS 1.4.3 (MRC Biostatistics Unit, Cambridge, and Imperial College School of Medicine, London, UK) and Microsoft-Excel-based network metaanalysis tool (NetMetaXL) [11]. Effect sizes for the Bayesian network meta-analysis were described with $95 \%$ credible interval. Statistical validity is guaranteed when the 95\% credible interval does not include 1 . The detailed data input form and initial data for the analysis of network meta-analysis can be found in the Additional file 1 .

\section{Results}

\section{Identification of relevant studies}

Figure 1 shows a flow diagram of how relevant studies were identified. A total of 946 articles were identified by searching 3 core databases and by hand searching the relevant bibliographies. In all, 307 duplicate articles and an additional 550 articles were excluded during the initial screening after reviewing the titles and abstracts. The full texts of the remaining 89 articles were thoroughly reviewed. Among these studies, 63 were excluded from the final analysis. The reasons for the exclusion of studies during the final review were as follows: review article $(n=19)$ or incomplete data $(n=45)$. The remaining $25 \mathrm{RCTs}$ were included in the final analysis. 


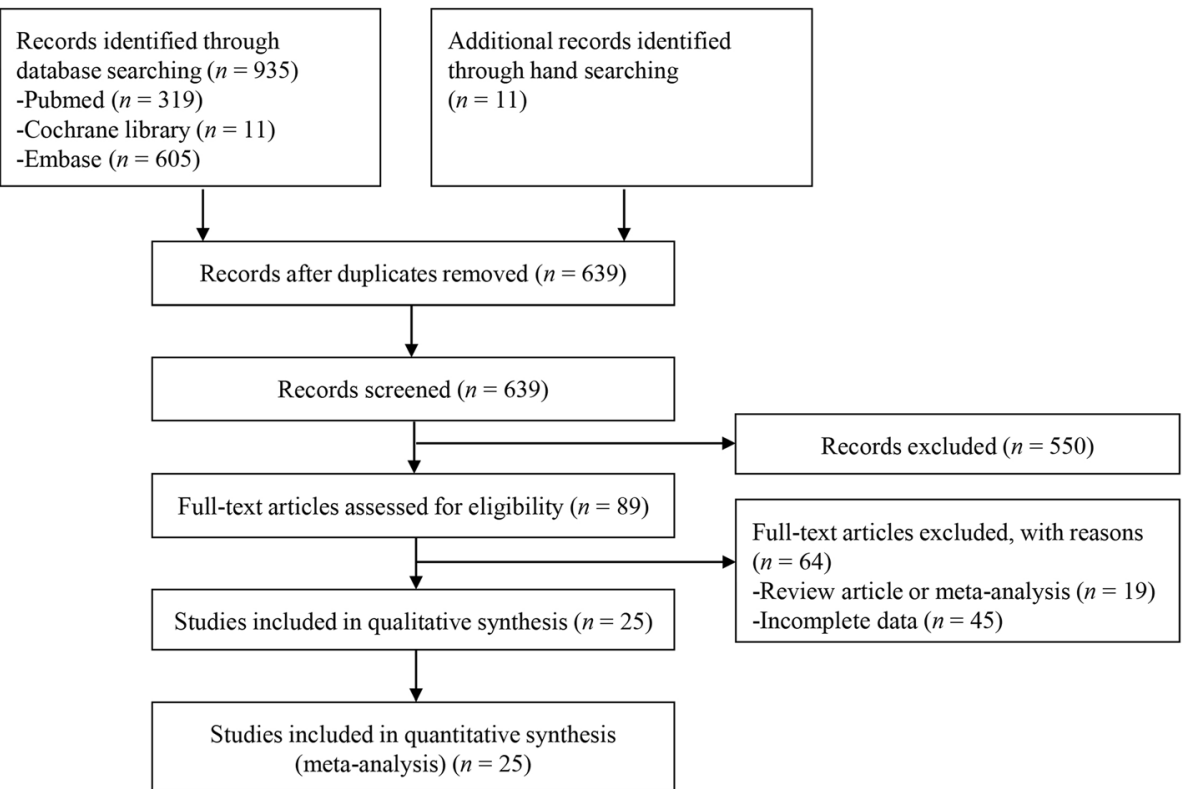

Fig. 1 Flow diagram for identification of relevant studies

Characteristics of studies included in the final analysis

In the 25 RCTs, we identified a total of 4473 participants (1602 placebo, 955 itopride, 773 domperidone, 713 acotiamide, 335 mosapride, 68 metoclopramide, and 27 trimebutine-treated participants). The enrolled studies were published between 1978 and 2012 [13-37]. All of the articles were full-text format except 2 studies [13, 36], which was in abstract format. More than half of the enrolled studies were conducted in Asia $(n=14)$ [13-26], followed by 9 studies in Europe [27-34], and the remaining 3 studies in the US [35-37]. Sixteen English-, 8 Chinese-, 1 Portuguese-, and 1 Korean-language studies were enrolled. The treatment duration ranged from 2 to 12 weeks. Eighteen studies used control medication as a placebo, whereas the remaining 8 studies performed direct head-to-head comparisons of prokinetic agents. All the prokinetic agents were orally administered and the detailed dosage, duration of prokinetics, and characteristics of the enrolled studies are shown in Table 1.

Figure 2 shows the network plot of relevant studies. Circles represent each prokinetic drug as a node and lines represent the direct comparisons. The extent of the circle indicates the number of included participants for each prokinetic drug, and the line thickness indicates the number of studies included in each comparison. Placebo was the biggest node, while the node size of metoclopramide and trimebutine was relatively smaller than the other remaining prokinetics. Direct comparisons were made between $B$ (itopride) and D (domperidone) and between $B$ (itopride) and $C$ (mosapride). The remaining comparisons were performed in a pairwise manner.

\section{Comparative efficacy of prokinetics in FD}

Figure 3 shows the Forest plot of the results from a Bayesian network meta-analysis of the enrolled studies. The fixed-effect model was adopted based on the DIC statistics. The relative efficacy is plotted as OR with $95 \%$ credible interval. Based on these results, we calculated the surface under the cumulative ranking curve (SUCRA), which is the converted value reflecting the probability of a treatment being the best according to the ranking of each treatment [11]. Table 2 shows the SUCRA of each treatment regimen. A higher SUCRA value indicates better therapeutic results based on the indirect comparison method [38]. Metoclopramide showed the best SUCRA probability $(92.5 \%)$, followed by trimebutine (74.5\%), mosapride (63.3\%), domperidone (62.9\%), itopride (32.4\%), acotiamide $(24.3 \%)$, and placebo.

However, the therapeutic efficacy of metoclopramide was not significantly different from that of trimebutine (OR: 1.32, 95\% credible interval: 0.27-6.06), mosapride (OR: 1.99, 95\% credible interval: 0.87-4.72), and domeperidone (OR: 2.04, 95\% credible interval: 0.92-4.60) in the league table, which shows the relative efficacy using OR and 95\% credible interval (Table 3). Metoclopramide showed better efficacy than itopride (OR: $2.79,95 \%$ credible interval: 1.29-6.21) and acotiamide (OR: 3.07, 95\% credible interval: 1.43-6.75). Domperidone also showed better efficacy than itopride (OR: 1.37, 95\% credible interval: $1.07-1.77$ ) and acotiamide (OR: 1.51, 95\% credible interval: 1.04-2.18).

Figure 4 shows the inconsistency plot of the enrolled studies. The plot demonstrates the posterior mean deviance of each study for the consistency model (horizontal 


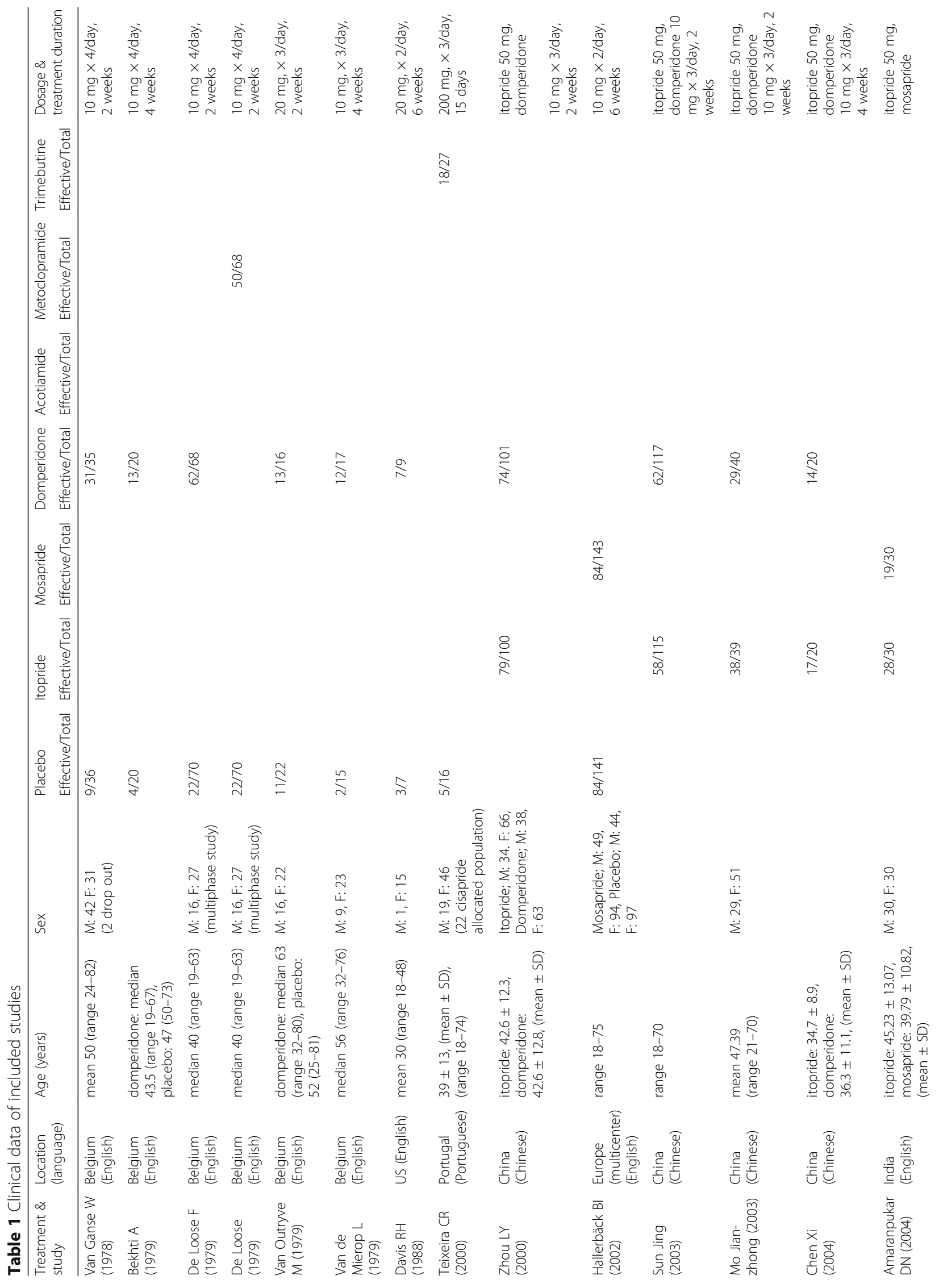




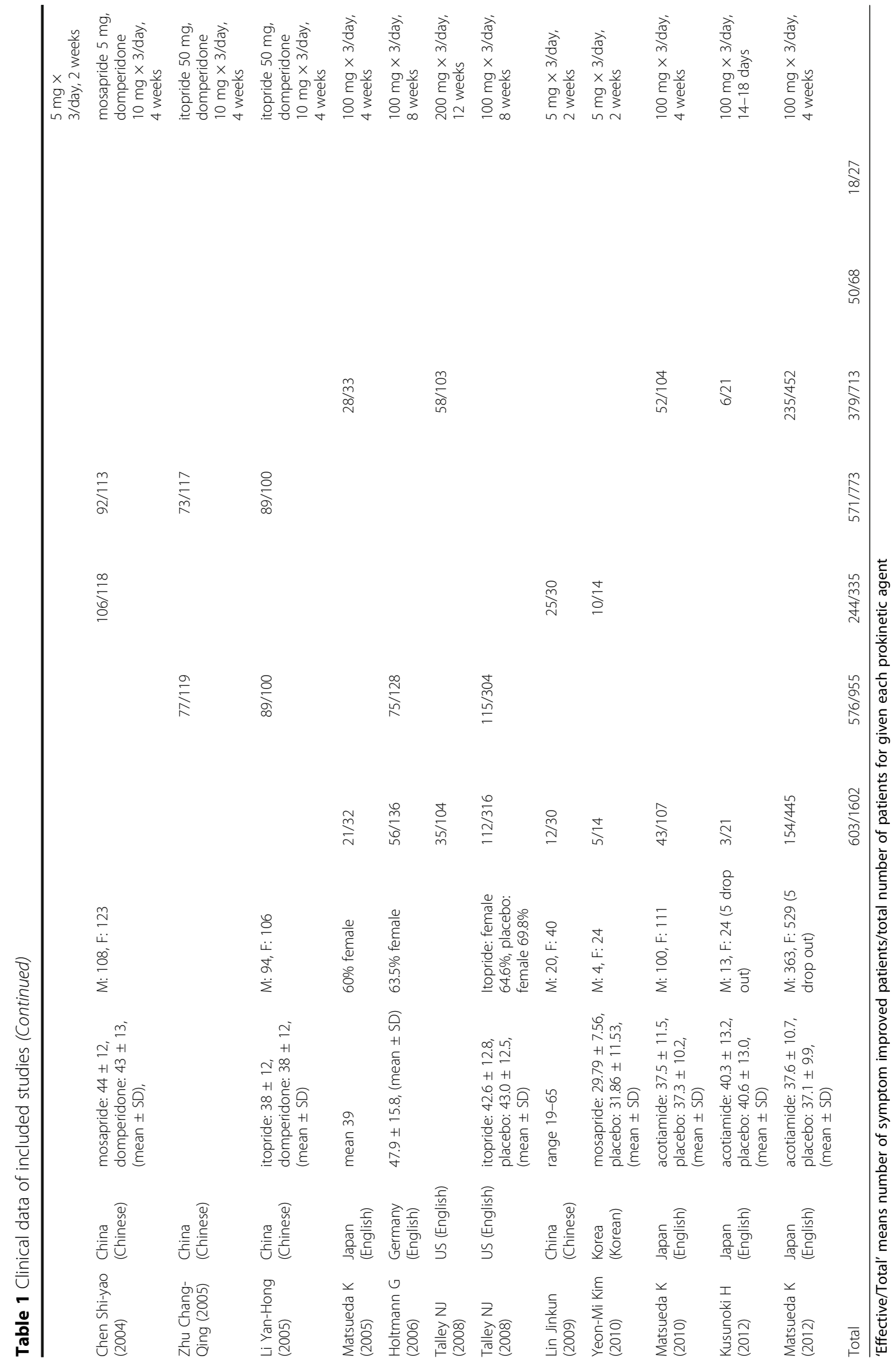




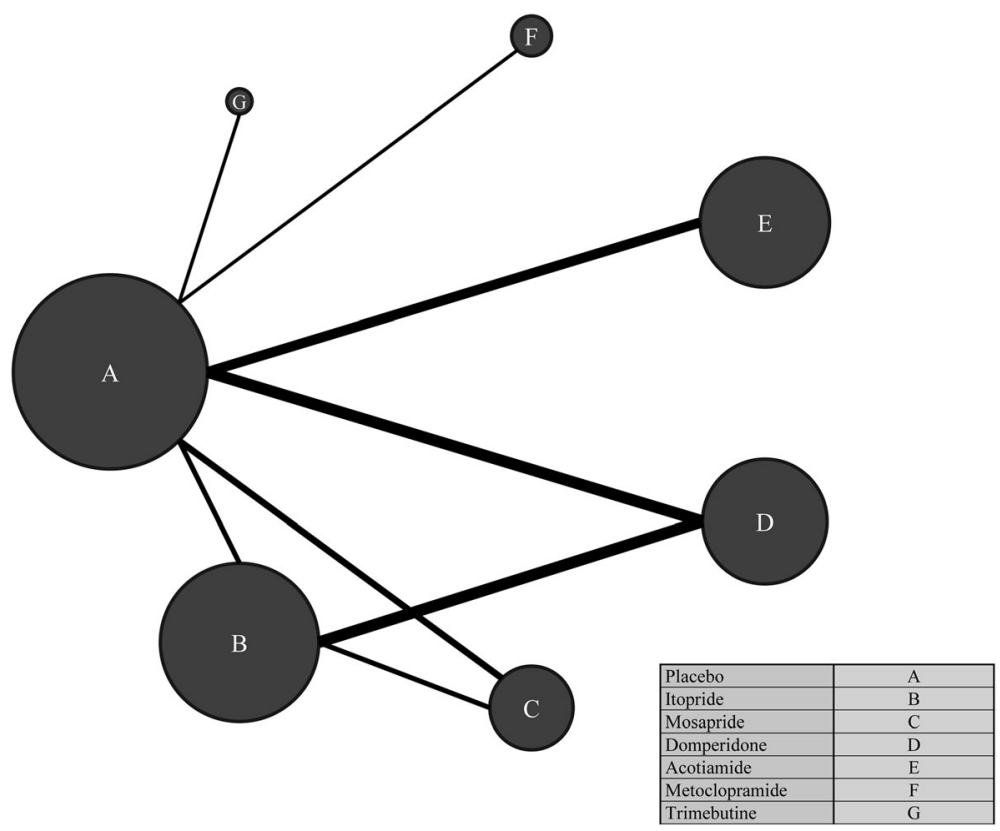

Fig. 2 Network plot of relevant studies. Circles represent the each prokinetic drug as a node and lines represent the direct comparisons. The extent of circle indicates the number of included participants in each prokinetic drug and the line thickness indicates the number of studies included in each comparison

axis), and the unrelated mean-effects model (vertical axis), along with the line of equality. There is some probability of inconsistency in the plot.

\section{Adverse events related to prokinetics}

Adverse events related to prokinetics were as follows; domperidone induced diarrhea, constipation, intestinal colic, galactorrhea, bilateral breast tenderness, hyperprolactinemia, headache, dizziness, insomnia, and skin scare [19, 28, 35]; mosapride induced diarrhea, constipation, abdomen pain, dry mouth, fatigue, dizziness, headache, leg pain, and nausea [33]; itopride induced abdomen pain, diarrhea, constipation, nausea, and hyperprolactinemia [34, 38]; Acotiamide induced headache, diarrhea, increase in serum alanine aminotransferase, potassium, triglycerides, $\gamma$-glutamyltransferase, nasopharyngitis, and

Table 2 SUCRA of each treatment regimen

\begin{tabular}{ll}
\hline Treatment & ${ }^{\text {aSUCRA }}$ \\
\hline Metoclopramide & 0.925 \\
Trimebutine & 0.745 \\
Mosapride & 0.633 \\
Domperidone & 0.629 \\
Itopride & 0.324 \\
Acotiamide & 0.243 \\
Placebo & 0.002 \\
\hline
\end{tabular}

${ }^{\mathrm{a}}$ SUCRA, surface under the cumulative ranking curve hyperprolactinemia [24-26]. Even control groups using placebo showed similar adverse events with treatment group taking prokinetics. Most adverse events were mild to moderate and have resolved after discontinuing prokinetics.

\section{Methodological quality}

For the methodological quality of enrolled studies, the exact determination of random sequence generation and allocation concealment was not available, and doubleblinding was not consistent in all of the enrolled studies. The summary of the risk of bias is demonstrated in Fig. 5 , and the risk of bias table of all enrolled studies is shown in Fig. 6.

\section{Discussion}

FD involves complex pathophysiologic mechanisms including visceral hypersensitivity, impaired gastric accommodation, delayed gastric emptying, H. pylori infection, psychosocial disorders, and even an unhealthy lifestyle [39-41]. The prevalence of gastric emptying delay was reported to be $37-39 \%$ in patients with FD. Consequently, prokinetics were developed based on the concept that promoting impaired gut motility could reduce the symptoms of FD $[39,40]$. However, improved delayed gastric emptying was not associated with symptomatic relief in patients with gastroparesis $[39,40]$. It is apparent that dysmotility cannot be the only target. 


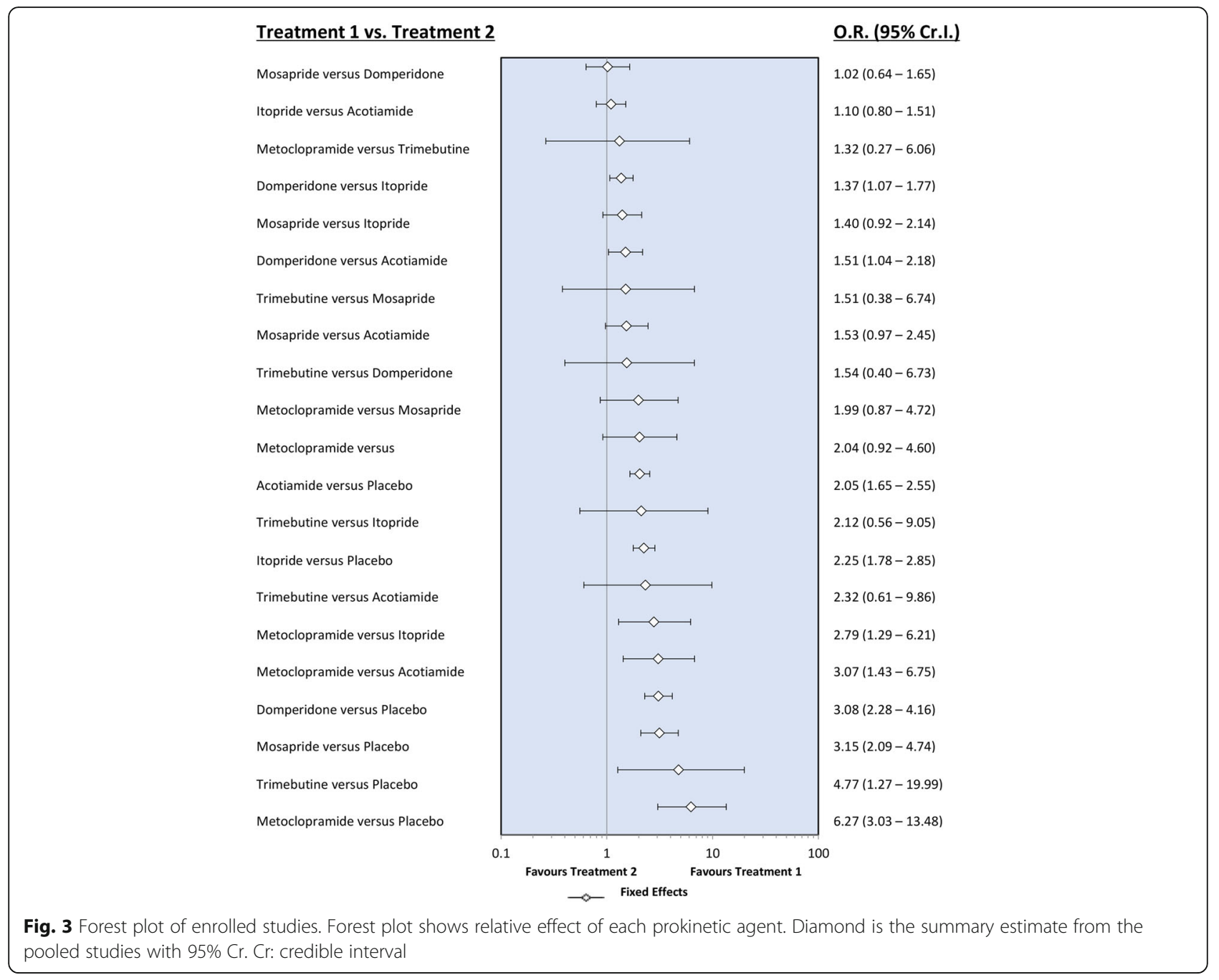

Multiple other mechanisms should be considered in the treatment of FD.

Proton-pump inhibitors (PPI) and prokinetic agents are the mainstays of the treatment of FD [39], both of which have similar relative efficacy [42]. However, adverse events related to PPI have been reported, and the comparative efficacy of prokinetics has thus far not been evaluated [43, 44]. Because the adverse events associated with PPIs are linked to long-term use of this medication and the recurrence of FD is not infrequent [45], repeated prescriptions of PPI should be re-evaluated and additional focus should be

Table 3 League table of each treatment regimen

\begin{tabular}{llllll}
\hline Metoclopramide & & & & & \\
$1.32(0.27-6.06)$ & Trimebutine & & & & \\
$1.99(0.87-4.72)$ & $1.51(0.38-6.74)$ & Mosapride & & & \\
$2.04(0.92-4.60)$ & $1.54(0.40-6.73)$ & $1.02(0.64-1.65)$ & Domperidone & & \\
$2.79(1.29-6.21)$ & $2.12(0.56-9.05)$ & $1.40(0.92-2.14)$ & $1.37(1.07-1.77)$ & Itopride & Itopride \\
$3.07(1.43-6.75)$ & $2.32(0.61-9.86)$ & $1.53(0.97-2.45)$ & $1.51(1.04-2.18)$ & $1.10(0.80-1.51)$ & $2.05(1.65-2.55)$ \\
$6.27(3.03-13.48)$ & $4.77(1.27-19.99)$ & $3.15(2.09-4.74)$ & $3.15(2.09-4.74)$ & $2.25(1.78-2.85)$ & Placebo
\end{tabular}

Odds ratio with $95 \%$ credible interval is described in each column. Prokinetic agent in the top left means better efficacy and statistical validity is guaranteed when the $95 \%$ credible interval does not include 1 


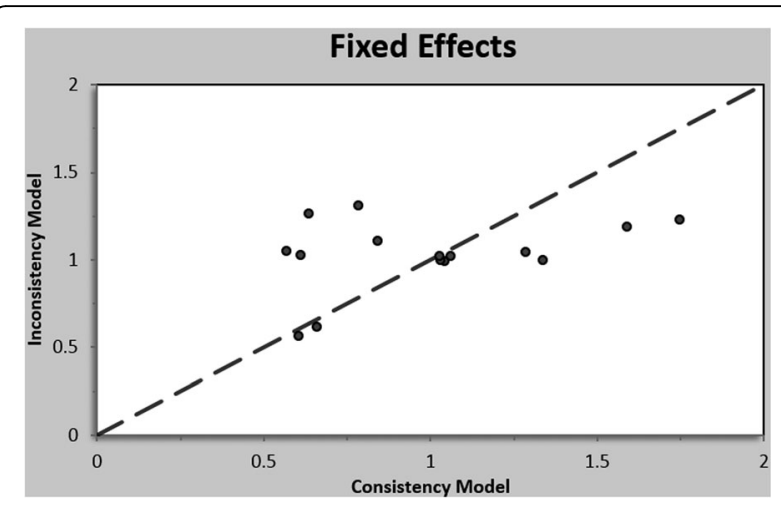

Fig. 4 Inconsistency plot of enrolled studies. Plot of the posterior mean deviance of each study for the consistency model (horizontal axis), and the unrelated mean-effects model (vertical axis), along with the line of equality

directed toward the role of prokinetic agents in the treatment of FD.

In this analysis, the relative efficacy of prokinetics was based on the SUCRA value. However, there was no significant difference in efficacy between the prokinetics including metoclopramide, trimebutine, mosapride, and domperidone (Table 3). Though the mechanisms of action of these medications are slightly different, the precise reason for the superior or inferior comparative efficacy between these medications could not be evaluated in this analysis. For example, although mosapride, itopride, and acotiamide are all known to modulate gastric accommodation, the statistical effects of these drugs differed in this analysis [46-48].

The frequency of adverse event must also be considered in selecting prokinetics for the treatment of FD. In the case of metoclopramide, which is a central $D_{1}$ and $D_{2}$ receptor antagonist, extrapyramidal symptoms including dystonic movement or tardive dyskinesia, which are often irreversible, inhibit the administration of high doses or the long-term use of this medication [49].
In addition to the occurrence of adverse events, drug incompatibility due to drug interactions from a combination of prokinetics or other drugs should be considered in selecting prokinetics. Because domperidone, which is a peripheral $D_{2}$ and $D_{3}$ receptor antagonist is associated with ventricular arrhythmia, concomitant use of drugs that prolong the QTc interval, and potent CYP3A4 inhibitors should be avoided [50].

With respect to serotonergic agonists, targeting multiple receptors with non-selective inhibition can potentially lead to adverse events. Cardiac arrhythmia or QTc prolongation was most commonly associated with cisapride and tegaserod [51]. $5 \mathrm{HT}_{1}$ receptor subtypes have been suggested to account for adverse events due to interactions with HERG cardiac potassium channel and 5-hydroxytryptamine [52]. Mosapride, which is a nonselective $5-\mathrm{HT}_{4}$ agonist with no $\mathrm{HERG}$ or $5 \mathrm{HT}_{1}$ affinity, could be substituted for metoclopramide or domperidone for the specific subset of patients who need long-term treatment.

Trimebutine, which is an enkephalin agonist, has a dual action on both of hyperkinetic and hypokinetic motility disorders [53]. This medication accelerates gastric emptying by inducing premature phase III activity of the migrating motor complex in gut [9]. Although most studies are focused on the treatment of irritable bowel syndrome, this medication could be substituted for other prokinetics that potentially have serious adverse effects.

In this study, we could not investigate the reason for the relatively lower efficacy of itopride, a mixed $D_{2}$ receptor antagonist, and acetylcholinesterase inhibitor or acotiamide, an $\mathrm{M}_{1} / \mathrm{M}_{2}$ muscarinic receptor antagonist and acetylcholinesterase inhibitor. Given the probability of inconsistencies in the enrolled studies and the superior efficacy of prokinetics that have a relatively small number of enrolled population, there could be an overestimation of efficacy drawn from the pairwise indirect comparison.

This study is the first meta-analysis evaluating the comparative effectiveness of prokinetic agents. The strength of

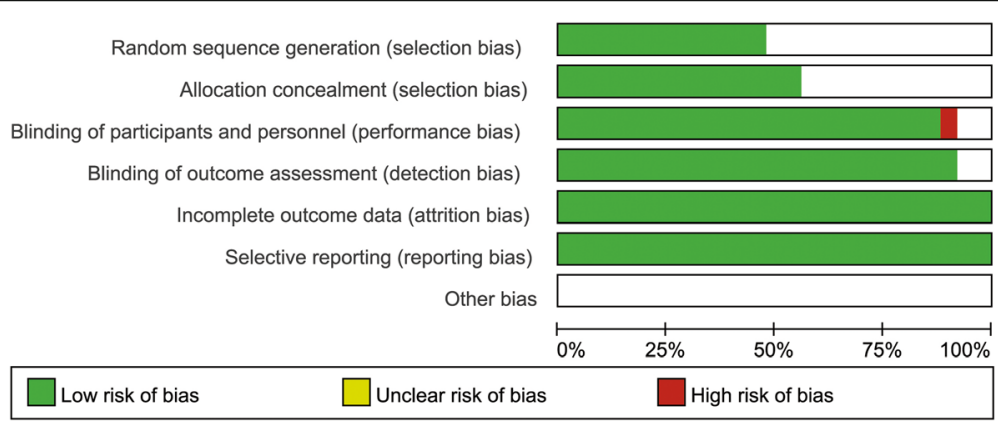

Fig. 5 Summary of risk of bias. This figure summarizes the risk of bias for each study as a risk of bias summary of the overall meta-analysis. Green represents low risk of bias and red represents high risk of bias 


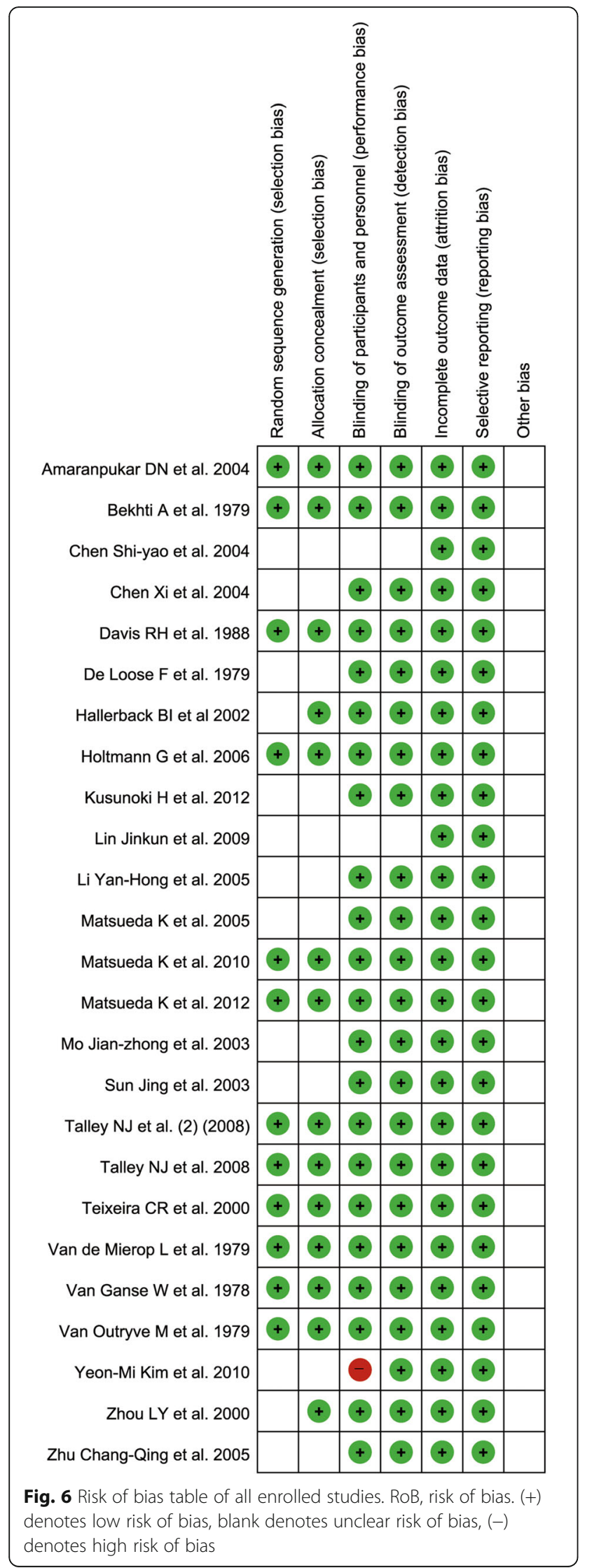

this study is the rigorous searching of the literature without language limitations and the use of an indirect comparative method to address the challenge of performing head-tohead analyses in clinical practice. Nonetheless, there are several limitations that impact the generalizability of the main results. All of the available prokinetic drugs could not be included in this study. These omitted agents include levosulpiride, a selective $\mathrm{D}_{2}$ receptor antagonist, erythromycin, a motilin receptor agonist, tandospirone, a $5 \mathrm{HT}_{1 \mathrm{~A}}$ agonist, prucalopride, a selective $5 \mathrm{HT}_{4}$ agonist or DA9701, a $5 \mathrm{HT}_{4}$ agonist, $\mathrm{D}_{2}$ receptor and $5 \mathrm{HT}_{3}$ antagonist. These medications are not available in some countries. Furthermore, levosulpiride is associated with drug-induced parkinsonism, inhibiting its wide application in clinical practice [54]. Prucalopride was developed and licensed for the treatment of constipation. Therefore, these drugs were excluded from the beginning of this study. Another limitation was the lack of data for some prokinetic agents in this analysis. The relatively small number of studies evaluating metoclopramide and trimebutine may in part explain the inconsistencies as well as the overestimation of the comparative effectiveness of some medications. In addition, most enrolled studies did not discriminate between epigastric pain and postprandial distress syndromes, which are subtypes of FD or post-infectious FD. Moreover, H. pylori infection, which is closely associated with the pathogenesis of FD, was not considered in most of the studies [39]. Overlap syndrome (FD + gastroesophageal reflux disease or FD + irritable bowel syndrome) which is frequently encountered in clinical practice, was also not considered [39]. A further limitation was the absence of a no common validated outcome measurement scale for all the enrolled studies. As we have noted in a previous study, there is no definite and unanimous way of defining symptomatic improvement in patients with FD [6]. Further studies that include newer prokinetics and control for the abovementioned limitations are needed to confirm the results of this study.

\section{Conclusion}

In conclusion, metoclopramide, trimebutine, mosapride, and domperidone showed better efficacy for the treatment of FD than that of itopride or acotiamide. Considering the adverse events related to metoclopramide or domperidone, the short-term use of these agents or the alternative use of trimebutine or mosapride could be recommended for the symptomatic relief of FD.

\section{Additional file}

Additional file 1: Contains tables for data input form and initial data for the analysis of network meta-analysis. (XLSX $17.6 \mathrm{~kb}$ ) 


\section{Abbreviations}

FD: Functional dyspepsia; OR: Odds ratio; PPI: Proton pump inhibitor; RCT: Randomized controlled trial; RoB: Risk of bias; SUCRA: Surface under the cumulative ranking curve

\section{Acknowledgements}

none.

\section{Funding}

This research was supported by Hallym University Research Fund (HURF-2015-18).

\section{Availability of data and materials}

Input data for the analyses are available from the corresponding author on request.

\section{Authors' contributions}

YJY participated data analysis and interpretation, and article drafting. CSB participated to study design, data analysis and interpretation, article drafting and gave final approval for publication. GHB participated to data analysis and interpretation. TYP participated to data analysis and interpretation. SPS participated to data analysis and interpretation. KTS participated to data analysis and interpretation. DJK participated to data analysis and interpretation. All authors have read and approved the final version of this manuscript.

\section{Ethics approval and consent to participate} Not applicable.

\section{Consent for publication}

Not applicable.

\section{Competing interests}

The authors declare that they have no competing interests.

\section{Publisher's Note}

Springer Nature remains neutral with regard to jurisdictional claims in published maps and institutional affiliations.

\section{Received: 8 January 2017 Accepted: 20 June 2017}

\section{Published online: 26 June 2017}

\section{References}

1. El-Serag HB, Talley NJ. Systemic review: the prevalence and clinical course of functional dyspepsia. Aliment Pharmacol Ther. 2004;19(6):643-54.

2. Stanghellini V, Chan FK, Hasler WL, Malagelada JR, Suzuki H, Tack J, et al. Gastroduodenal Disorders. Gastroenterology. 2016;150(6):1380-92.

3. Drossman DA, Dumitrascu DL. Rome III: new standard for functional gastrointestinal disorders. J Gastrointestin Liver Dis. 2006;15(3):237-41.

4. Moayyedi P, Soo S, Deeks J, Delaney B, Innes M, Forman D. Pharmacological interventions for non-ulcer dyspepsia. Cochrane Database Syst Rev. 2006; 18(4):Cd001960

5. Miwa H, Ghoshal UC, Gonlachanvit S, Gwee KA, Ang TL, Chang FY, et al. Asian consensus report on functional dyspepsia. J Neurogastroenterol Motil. 2012;18(2):150-68.

6. Bang CS, Kim JH, Baik GH, Kim HS, Park SH, Kim EJ, et al. Mosapride treatment for functional dyspepsia: a meta-analysis. J Gastroenterol Hepatol. 2015:30(1):28-42.

7. Huang $X$, Lv B, Zhang S, Fan YH, Meng LN. Itopride therapy for functional dyspepsia: a meta-analysis. World J Gastroenterol. 2012;18(48):7371-7.

8. Hiyama T, Yoshihara M, Matsuo K, Kusunoki H, Kamada T, Ito M, et al. Treatment of functional dyspepsia with serotonin agonists: a meta-analysis of randomized controlled trials. J Gastroenterol Hepatol. 2007;22(10):1566-70.

9. Hiyama T, Yoshihara M, Matsuo K, Kusunoki H, Kamada T, Ito M, et al. Treatment of functional dyspepsia with serotonin agonists: a meta-analysis of randomized controlled trials. J Gastroenterol Hepatol. 2007;22(3):304-10.

10. Xiao G, Xie X, Fan J, Deng J, Tan S, Zhu Y, et al. Efficacy and safety of acotiamide for the treatment of functional dyspepsia: systematic review and meta-analysis. ScientificWorldJournal. 2014;2014:541950.

11. Brown S, Hutton B, Clifford T, Coyle D, Grima D, Wells G, et al. A Microsoftexcel-based tool for running and critically appraising network metaanalyses-an overview and application of NetMetaXL. Syst Rev. 2014;3:110.
12. Higgins JP. Green S. Cochrane handbook for systematic reviews of interventions. Version 5.1. 0. The Cochrane Collaboration; 2011. 2013.

13. Matsueda K, Hongo M, Sasaki D, Kusano M, Harasawa S, Arakawa T, et al. Therapeutic efficacy of novel agent (Z-338) in functional dyspepsia (FD). Gastroenterology. 2005;128(Suppl 2):A467.

14. Zhou LY, Li BC, Lin SL, Li AY, Dong XY, Li ZS, et al. A multi-centre clinical trial on Itopride hydrochloride for treatment of functional dyspepsia. Zhongguo Linchuang Yaolixue Zazhi. 2000;16:403-7.

15. Sun J, Zhang CL, Chu Y, Yuan YZ, Li ZS, Liu XG, et al. A multi-center, doubleblind, randomized and controlled trial of itopride hydrochloride in treatment of functional dyspepsia. Shanghai Yixue. 2003;26:227-9.

16. Mo JZ, Li DG, Jiang JH, Jiang YB, Wang XP, Gong ZH, et al. A multi-center clinical trial of itopride hydrochloride in the treatment of functional dyspepsia. Zhongguo Xinyao Zazhi. 2003;12:467-9.

17. Chen X, Hu NZ, Xie HJ, Li BK, Xu JM. Effect of itopride hydrochloride on functional dyspepsia. Zhongguo Linchuang Yaolixue Zazhi. 2004;20:25-9.

18. Amarapurkar DN, Rane P. Randomised, double-blind, comparative study to evaluate the efficacy and safety of ganaton (itopride hydrochloride) and mosapride citrate in the management of functional dyspepsia. J Indian Med Assoc. 2004;102(12):735-77. 760

19. Chen SY, Wang JY, Zhu CW, Yuan YZ, Zou B, Xia L, et al. A randomized controlled multi-center clinical trial on mosapride in the treatment of functional dyspepsia. Chin J Epidemiol. 2004;25(2):165-8.

20. Zhu CQ, Mao YM, Zeng MD, Dong SX, Xu GM, Wang GS, et al. A clinical study of hydrochloride itopride in the treatment of functional dyspepsia. Zhongguo Yaoke Daxue Xuebao. 2005;6:580-3.

21. Li YH, Gong PL, Hou XH, Chen J, Liu NZ, Tian DA, et al. Itopride in treatment of 104 patients with functional dyspepsia: a randomized, double-blind controlled clinical trial. Zhongguo Xinyao Yu Linchuang Zazhi. 2005;7:524-8.

22. Lin J, Ren M, Peng $X$, Xiao $Y$, Wang $S$, Yang $L$, et al. Short-term efficacy of mosapride dispersible tablet on postprandial distress syndrome. Chin J Gastroenterol. 2009:14(8):488-90.

23. Kim YM, Park YC, Jo JH, Kang WC, Son MW, Hong KE. Effect of herb medicine treatment for functional dyspepsia: a randomized placebocontrolled and compared standard treatment trial. J Korean Orient Med. 2010;31(1):1-13.

24. Matsueda K, Hongo M, Tack J, Aoki H, Saito Y, Kato H. Clinical trial: dosedependent therapeutic efficacy of acotiamide hydrochloride (Z-338) in patients with functional dyspepsia - $100 \mathrm{mg}$ t.l.D. Is an optimal dosage. Neurogastroenterol Motil. 2010;22(6):618-e173.

25. Kusunoki H, Haruma K, Manabe N, Imamura H, Kamada T, Shiotani A, et al Therapeutic efficacy of acotiamide in patients with functional dyspepsia based on enhanced postprandial gastric accommodation and emptying: randomized controlled study evaluation by real-time ultrasonography. Neurogastroenterol Motil. 2012;24(6):540-5. e250-1.

26. Matsueda K, Hongo M, Tack J, Saito Y, Kato H. A placebo-controlled trial of acotiamide for meal-related symptoms of functional dyspepsia. Gut. 2012; 61(6):821-8

27. Van Ganse W, Van Damme L, Van de Mierop L, Deruyttere M, Lauwers W, Coegegrachts J. Chronic dyspepsia: double-blind treatment with domperidone (R 33812) or a placebo. A multicentre therapeutic evaluation. Curr Ther Res. 1978;23(11):695-701.

28. Bekhti A, Rutgeerts L. Domperidone in the treatment of functional dyspepsia in patients with delayed gastric emptying. Postgrad Med J. 1979; 55(Suppl 1):30-2.

29. De Loose F. Domperidone in chronic dyspepsia: a pilot open study and a multicentre general practice crossover comparison with metoclopramide and placebo. Pharmatherapeutica. 1979;2:140-6.

30. Van Outryve M, Lauwers W, Verbeke S. Domperidone for the symptomatic treatment of chronic post-prandial nausea and vomiting. Postgrad Med J. 1979;55(Suppl 1):33-5

31. Van de Mierop L, Rutgeerts L, Van den Langenbergh B, Staessen A. Oral domperidone in chronic postprandial dyspepsia. Digestion. 1979;19(4):244-50.

32. Teixeira CR, Abdalla Kurban AC, Denicol IP, Vieira Coelho NH, Spinato Torresini RJ, Peter RB. Randomized, double-blind study of functional dyspepsia with cisapride, trimebutine and placebo - relationship with variation of the gastric emptying time. Rev Bras Med. 2000;57(7):729-35

33. Hallerbäck B, Bommelaer G, Bredberg E, Campbell M, Hellblom M Lauritsen $K$, et al. Dose finding study of mosapride in functional dyspepsia: a placebo-controlled, randomized study. Aliment Pharmacol Ther. 2002;16(5):959-67. 
34. Holtmann G, Talley NJ, Liebregts T, Adam B, Parow C. A placebo-controlled trial of itopride in functional dyspepsia. N Engl J Med. 2002;354(8):832-40.

35. Davis RH, Clench MH, Mathias JR. Effects of domperidone in patients with chronic unexplained upper gastrointestinal symptoms: a double-blind, placebo-controlled study. Dig Dis Sci. 1988;33(12):1501-11.

36. Talley NJ, Tack JF, Kowalski DL, Borton MA, Brave A. 1053 a novel acetylcholine esterase inhibitor Acotiamide hydrochloride (YM443) in functional dyspepsia: efficacy in a randomized, double-blind, placebocontrolled dose ranging trial. Gastroenterology. 2008;134:A-157-A-8.

37. Talley NJ, Tack J, Ptak T, Gupta R, Giguère M. Itopride in functional dyspepsia: results of two phase III multicentre, randomised, double-blind, placebo-controlled trials. Gut. 2008;57(6):740-6.

38. Salanti G, Ades AE, loannidis JP. Graphical methods and numerical summaries for presenting results from multiple-treatment meta-analysis: an overview and tutorial. J Clin Epidemiol. 2011;64(2):163-71.

39. Miwa H, Kusano M, Arisawa T, Oshima T, Kato M, Joh T, et al. Evidencebased clinical practice guidelines for functional dyspepsia. J Gastroenterol. 2015;50(2):125-39.

40. Quartero AO, de Wit NJ, Lodder AC, Numans ME, Smout AJ, Hoes AW. Disturbed solid-phase gastric emptying in functional dyspepsia: a metaanalysis. Dig Dis Sci. 1998;43(9):2028-33.

41. Lunding JA, Tefera S, Gilja OH, Hausken T, Bayati A, Rydholm H, et al. Rapid initial gastric emptying and hypersensitivity to gastric filling in functional dyspepsia: effects of duodenal lipids. Scand J Gastroenterol. 2006;41(9): 1028-36.

42. Hsu YC, Liou JM, Yang TH, Hsu WL, Lin HJ, Wu HT, et al. Proton pump inhibitor versus prokinetic therapy in patients with functional dyspepsia: is therapeutic response predicted by Rome III subgroups? J Gastroenterol. 2011:46(2):183-90

43. Atkinson NS, Reynolds DJ, Travis SP. 'Lemonade Legs': why do some patients get profound hypomagnesaemia on Proton-pump inhibitors? Intest Res. 2015;13(3):227-32.

44. Lazarus B, Chen Y, Wilson FP, Sang Y, Chang AR, Coresh J, et al. Proton pump inhibitor use and the risk of chronic kidney disease. JAMA Intern Med. 2016;176(2):238-46.

45. Meineche-Schmidt V, Talley NJ, Pap A, Kordecki H, Schmid V, Ohlsson L, et al. Impact of functional dyspepsia on quality of life and health care consumption after cessation of antisecretory treatment. A multicentre 3month follow-up study. Scand J Gastroenterol. 1999;34(6):566-74.

46. Amano T, Ariga H, Kurematsu A, Yamato S, Morioka S, Masaka A, et al. Effect of 5-hydroxytryptamine receptor 4 agonist mosapride on human gastric accommodation. Neurogastroenterol Motil. 2015;27(9):1303-9.

47. Iwanaga Y, Miyashita N, Saito T, Morikawa K, Itoh Z. Gastroprokinetic effect of a new benzamide derivative itopride and its action mechanisms in conscious dogs. Jpn J Pharmacol. 1996;71(2):129-37.

48. Seto K, Sasaki T, Katsunuma K, Kobayashi N, Tanaka K, Tack J. Acotiamide hydrochloride (Z-338), a novel prokinetic agent, restores delayed gastric emptying and feeding inhibition induced by restraint stress in rats. Neurogastroenterol Motil. 2008;20(9):1051-9.

49. Ganzini L, Casey DE, Hoffman WF, McCall AL. The prevalence of metoclopramide-induced tardive dyskinesia and acute extrapyramidal movement disorders. Arch Intern Med. 1993;153(12):1469-75.

50. Ehrenpreis ED, Roginsky G, Alexoff A, Smith DG. Domperidone is commonly prescribed with QT-interacting drugs: review of a community-based practice and a Postmarketing adverse drug event reporting database. J Clin Gastroenterol. 2017;51(1):56-62.

51. Quigley EM. Prokinetics in the management of functional gastrointestinal disorders. J Neurogastroenterol Motil. 2015;21(3):330-6.

52. Tack J, Camilleri M, Chang L, Chey WD, Galligan JJ, Lacy BE, et al. Systematic review: cardiovascular safety profile of 5-HT(4) agonists developed for gastrointestinal disorders. Aliment Pharmacol Ther. 2012;35(7):745-67.

53. Lüttecke K. A trial of trimebutine in spastic colon. J Int Med Res. 1978;6(2):86-8.

54. Shin HW, Kim MJ, Kim JS, Lee MC, Chung SJ. Levosulpiride-induced movement disorders. Mov Disord. 2009;24(15):2249-53.

\section{Submit your next manuscript to BioMed Central and we will help you at every step:}

- We accept pre-submission inquiries

- Our selector tool helps you to find the most relevant journal

- We provide round the clock customer support

- Convenient online submission

- Thorough peer review

- Inclusion in PubMed and all major indexing services

- Maximum visibility for your research

Submit your manuscript at www.biomedcentral.com/submit
Biomed Central 